\title{
Application of Orthogonal Design to Optimize Extraction of Polysaccharide from Cynomorium songaricum Rupr (Cynomoriaceae)
}

\author{
Xiaoli Wang ${ }^{1}$, Fan Wang ${ }^{2}$, Yanjun Jing ${ }^{2}$, Yonggang $\mathrm{Wang}^{2}$, Peng Lin $^{2}$ and Lin \\ Yang ${ }^{2 *}$ \\ ${ }^{1}$ Lanzhou Institute of Husbandry and Pharmaceutical Sciences of Chinese Academy of Agricultural Sciences, ${ }^{2}$ School of Life \\ Science and Engineering, Lanzhou University of Technology, Lanzhou, China
}

*For correspondence: Email: 412316788@163.com; Tel: +86-309312976707; Fax: +86-309312976707

\begin{abstract}
Purpose: To optimize the extraction technology of polysaccharides from Cynomorium songaricum Rupr by ultrasonic-assisted extraction (UAE).

Methods: Four parameters including ultrasonic power, ratio of raw material to water, extraction temperature, and extraction time were optimized by orthogonal design. The effects of the factors on the yield of polysaccharides were also studied. The hydroxyl and 1,1-diphenyl-2-picrylhydrazyl (DPPH) radical scavenging activities were determined in vitro by spectrophotometry.

Results: The optimal conditions were as follows: 1:30 as ratio of raw material to water, extraction for 70 min at $80^{\circ} \mathrm{C}$ with ultrasonic power being $420 \mathrm{~W}$. Under these conditions, the yield of polysaccharides was up to $4.51 \%$, which was significantly higher than that obtained under the initial conditions (3.82\%). $D P P H$ radical scavenging activity reached $64.82 \%$ at $0.012 \mathrm{mg} / \mathrm{mL}$, while hydroxyl radical scavenging activity was $18.36 \%$ at $0.5 \mathrm{mg} / \mathrm{mL}$.

Conclusion: Ultrasonic-assisted extraction technology is a useful tool for the extraction of bioactive components from biological materials.
\end{abstract}

Keywords: Cynomorium songaricum, Polysaccharide, Ultrasonic-assisted extraction, Orthogonal design

Tropical Journal of Pharmaceutical Research is indexed by Science Citation Index (SciSearch), Scopus, International Pharmaceutical Abstract, Chemical Abstracts, Embase, Index Copernicus, EBSCO, African Index Medicus, JournalSeek, Journal Citation Reports/Science Edition, Directory of Open Access Journals (DOAJ), African Journal Online, Bioline International, Open-J-Gate and Pharmacy Abstracts

\section{INTRODUCTION}

Cynomorium songaricum Rupr. (Cynomoriaceae) is an achlorophyllous holoparasite with distribution in northwestern China. Among its chemical constituents, steroids, triterpenes, flavonoids and lignans have been reported previously [1,2]. Stems of Cynomorium songaricum Rupr. are known as suo-yang in China. According to the ancient Chinese medical literature, $C$. songaricum is effective in regulating endocrinopathy and heightening sexual function and anti-aging such as dementia [3,4]. Because it works usually together with other Chinese herbs, its individual bioactivity has been scarcely studied.

Polysaccharide is one of common ingredients in many fruits with formidable health care functions in anti-tumor [5,6], antioxidation [7,8], antiinflammatory [9] and human immunity improvement [10]. The research which emphases on the modern medicine and functionalized food chemistry mainly focuses on 
the physiological activities and structures of polysaccharides. So far, a large number of researches on extraction technologies of various polysaccharides have been reported, including solvent extraction [11], biological enzymatic method [12] and ultrasonic extraction [13,14].

The aim of this study was to apply ultrasonicassisted extraction (UAE) to isolate polysaccharides from $C$. songaricum, and to optimize the extraction parameters using orthogonal design which is an effective method to evaluate the effects of multiple factors and their interaction on one or more response variables.

\section{EXPERIMENTAL}

\section{Material and reagents}

Cynomorium songaricum Rupr. (Cynomoriaceae) used in this study was provided by Yide biological Technology Co, Ltd (Guazhou, PR China). One hundred grams of $C$. songaricum was dried, ground to powder and then sieved through a mesh screen with size of aperture 370 $\mu \mathrm{m}$. All solvents were analytical grade and obtained from Beijing Solarbio Co, Ltd (Beijing, P.R China).

\section{Extraction and determination of polysaccharide}

Polysaccharide was extracted from the dried samples $(1.0 \mathrm{~g})$ by ultrasonic-assisted treatment in an ultrasonic processor (KQ-250DB, Kunshan Ultrasonic Instruments Co, Ltd, Jiangsu, China). Then, impurity proteins, vitamins, lipids and other pulp components were separated by centrifugation in a $50 \mathrm{~mL}$ centrifuge tube. The supernatant was collected and concentrated in a vacuum concentrator and precipitated with $80 \%$ ethanol, and then the precipitate was washed sufficiently with ethanol, and suspended by 100 $\mathrm{mL}$ of water. The solution was filtered later. The content of polysaccharide extracted from $C$. songaricum was measured by phenol-sulfuric acid method using glucose as standard [15]. The optical density of reaction solution was measured at $485 \mathrm{~nm}$. The content of polysaccharide in this study was calculated according to the equation of linear regression $\left(Y=12.6308 x-0.0144, R^{2}=\right.$ 0.9997 ) based on the standard curve of which horizontal coordinate and vertical coordinate denoted the concentration of glucose $(\mathrm{mg} / \mathrm{mL})$ and OD485, respectively. The yield of polysaccharide could be calculated as in Eq 1.
Polysaccharide yield $(\%)=(\mathrm{CNV}) / 1000 \mathrm{~W}) 1000$

where $\mathrm{C}$ is the concentration of polysaccharide calculated by the calibrated regression equation $(\mathrm{mg} / \mathrm{mL}), \mathrm{N}$ is the dilution factor, $\mathrm{V}$ is the total volume of extraction solution $(\mathrm{mL})$ and $W$ is the weight of raw material $(\mathrm{g})$.

\section{Single-factor test}

\section{Effect of ultrasonic power on the yield of polysaccharide}

The ultrasonic power was set at 240, 360, 480 and $600 \mathrm{~W}$, respectively, meanwhile, ratio of raw material to water, extraction temperature, extraction times and extraction duration were fixed at $1 ; 30,80{ }^{\circ} \mathrm{C}$, twice and $60 \mathrm{~min}$. Under these conditions, the content of polysaccharide extracted was determined by phenol-sulfuric acid method and calculated.

\section{Effect of ratio of raw material to water on the yield of polysaccharide}

The ultrasonic power, extraction temperature, extraction duration and extraction times were fixed at $480 \mathrm{~W}, 70{ }^{\circ} \mathrm{C}, 60 \mathrm{~min}$ and twice; in addition, the ratio of raw material to water was set at $1: 6,1: 10,1: 20,1: 30,1: 40$ and $1: 50 \mathrm{~g} / \mathrm{mL}$, respectively. Under these conditions, the content of polysaccharide extracted was determined by phenol-sulfuric acid method and calculated according to equation (1).

\section{Effect of extraction temperature on the yield of polysaccharide}

The extraction temperature was set at 60, 70, 80, and $90{ }^{\circ} \mathrm{C}$, with the ratio of raw material to water, ultrasonic power, extraction times, and extraction duration at 1:30, $480 \mathrm{~W}$, twice and $60 \mathrm{~min}$, respectively. The content of polysaccharide extracted was determined by phenol-sulfuric acid method and calculated as in Eq 1 above.

\section{Effect of extraction time on the yield of polysaccharide}

The extraction duration was set at $30,50,70$ and $90 \mathrm{~min}$, respectively, and ratio of raw material to water, ultrasonic power, extraction times, and extraction temperature were fixed at 1:30, 480 $\mathrm{W}$, twice and $80{ }^{\circ} \mathrm{C}$. The content of polysaccharide extracted was determined by phenol-sulfuric acid method and calculated as in Eq 1 above. 
Optimization of extraction conditions by orthogonal design

According to the results of the single factor experiment, orthogonal array $\left(\operatorname{L9}\left(3^{4}\right)\right)$ with four factors at three levels was chosen to seek the optimum conditions for the maximal yield of polysaccharide extracted from $C$. songaricum. Factors and its levels of orthogonal design were shown in Table 1 and the results of orthogonal test are shown in Table 2 and Table 3. Each of the 9 experiments was performed in triplicate.

\section{Analysis of variance}

Analysis of variance (ANOVA) is one of the most important statistical tools, which is used to uncover the main factor and interaction effects of variables. It is also used to identify the procedure parameters that are statistically significant. In ANOVA, $\mathrm{F}$ ratio is employed to recognize these significant parameters from others. $F$ value is the ratio of the variance estimation of the treatment effect to the variance estimation of the error. The large value of $F$ ratio means that the selected parameter has a significant effect on the evaluation index compared with the error variation. The sum of squares and degrees of freedom corresponding to the eliminated terms are added into the residual sum of squares and degree of freedom.

\section{Determination of antioxidant activity in vitro}

\section{Scavenging of DPPH radical assay}

The DPPH scavenging assay was performed according to the method of Shimada et al [16]. $0.2 \mathrm{mM}$ DPPH in $60 \%$ ethanol was prepared before UV measurements. Then, $3.0 \mathrm{~mL}$ of polysaccharide extracted from Cynomorium songaricum Rupr (0.002, 0.004, 0.008 and 0.012 $\mathrm{mg} / \mathrm{mL}$ ) was added into $1.0 \mathrm{~mL}$ DPPH, and kept at room temperature for $30 \mathrm{~min}$ in the dark. The absorbance of the solution was measured at 525 $\mathrm{nm}$ later. Ascorbic acid (0.002, 0.004, 0.008 and $0.012 \mathrm{mg} / \mathrm{mL}$ ) was used as positive controls.

The scavenging activity of DPPH radical (\%) was calculated according to the method of Shimada et al [16].

\section{Hydroxyl radical scavenging assay}

Hydroxyl radical scavenging activity was measured according to the method of Jin et al [17]. $10 \mathrm{~mL}$ reaction mixture is inclusive of $2 \mathrm{~mL}$ of $200 \mathrm{mM}$ sodium phosphate buffer ( $\mathrm{pH} 7.4), 1.5$ $\mathrm{mL}$ of $5.0 \mathrm{mM} \mathrm{1,} \mathrm{10-phenanthroline} \mathrm{aqueous}$ solution, $1.0 \mathrm{~mL}$ of $7.5 \mathrm{mM} \mathrm{FeSO}$ aqueous solution, $1.0 \mathrm{~mL}$ of $0.1 \% \mathrm{H}_{2} \mathrm{O}_{2}$ aqueous solution, $0.1 \mathrm{~mL}$ of the polysaccharide aqueous solution with different concentrations $(0.2,0.30,0.40$ and $0.50 \mathrm{mg} / \mathrm{mL}$ ) and $4.4 \mathrm{~mL}$ of distilled water. After incubated at $37^{\circ} \mathrm{C}$ for $1 \mathrm{~h}$, the absorbance of the mixture was measured at $510 \mathrm{~nm}$. The scavenging activity of hydroxyl radical production was calculated according to the method of Jin et al [17].

\section{Statistical analysis}

The values are expressed as means \pm standard deviation. Statistical analysis was done by Origin Lab software (version 8.0). ANOVA was used to analyze significant differences among the trails in the orthogonal design. The criterion for statistical significance was $p<0.05$, and extreme significance was $p<0.01$.

\section{RESULTS}

\section{Effect of ultrasonic power on yield of polysaccharides}

The effects of different ultrasonic powers on the yield of polysaccharides were investigated in the .commended study. As shown in Figure 1a, the extraction yield increased as the increase of ultrasonic power ranged from $240 \mathrm{~W}$ to $480 \mathrm{~W}$, and reached the maximum value at $480 \mathrm{~W}$.

\section{Effect of ratio of raw material to water on yield of polysaccharides}

The effects of different ratios of raw material to water, on the yield of polysaccharides were studied. As shown in Figure $1 \mathrm{~b}$, the extraction yield continued to increase evidently with the growth in the ratio of raw material to water until reaching at $1: 30 \mathrm{~g} / \mathrm{mL}$.

Table 1: Orthogonal factors and levels

\begin{tabular}{lcccc}
\hline Level & \multicolumn{4}{c}{ Factors } \\
\cline { 2 - 5 } & $\begin{array}{c}\boldsymbol{A} \text { (Ultrasonic } \\
\text { power } \text { W) }\end{array}$ & $\begin{array}{c}\text { B (ratio of raw material to } \\
\text { water } \mathbf{~} / \mathbf{m} \mathbf{L} \text { ) }\end{array}$ & $\begin{array}{c}\text { C (extraction } \\
\text { Temperature }{ }^{\circ} \boldsymbol{C} \text { ) }\end{array}$ & $\begin{array}{c}\text { D (extraction time } \\
\text { min) }\end{array}$ \\
\hline 1 & 420 & $1: 25$ & 75 & 60 \\
2 & 480 & $1: 30$ & 80 & 70 \\
3 & 540 & $1: 35$ & 85 & 80 \\
\hline
\end{tabular}




\section{Effect of extraction temperature on yield of polysaccharides}

The effects of different extraction temperature on the yield of polysaccharides were evaluated in this research. As was indicated in Figure 1c, the yield of polysaccharides was increasing all the time with the increase of extraction temperature range of $60 \sim 80^{\circ} \mathrm{C}$ and reached the peak value at $80{ }^{\circ} \mathrm{C}$. The yield of polysaccharides decreased when the extraction temperature exceeded 80 ${ }^{\circ} \mathrm{C}$.

\section{Effect of extraction time on extraction yield of polysaccharides}

The effect of extraction time on yield of polysaccharides from $C$. songaricum was shown in Figure 1d. It could be found that the extraction yield increased as extraction time ascended from 30 to $70 \mathrm{~min}$, peaked at $70 \mathrm{~min}$, and then decreased.
Optimization of extraction conditions of polysaccharides

Orthogonal array $\left(\operatorname{L9}\left(3^{4}\right)\right)$ was used to optimize the extraction parameters of polysaccharides. Results were shown in Table 2 and Table 3. There were nine experiments corresponding to the nine rows and four columns. Each experiment was repeated three times under the same conditions to eliminate the effects of noise sources in the process. The responses of all tests were given in Table 2. The significance of the factors was studied by ANOVA. The ANOVA summary was shown in Table 3 . The F-value was used for qualitative analysis of whether effective factors existed. Factors $A$ and $C$ are significant for the polysaccharide yield from $C$. songaricum at $99 \%$ confidence level. Meanwhile, factors $B$ and $D$ show less effect on the polysaccharide yield from $C$. songaricum at the $90 \%$ confidence level.
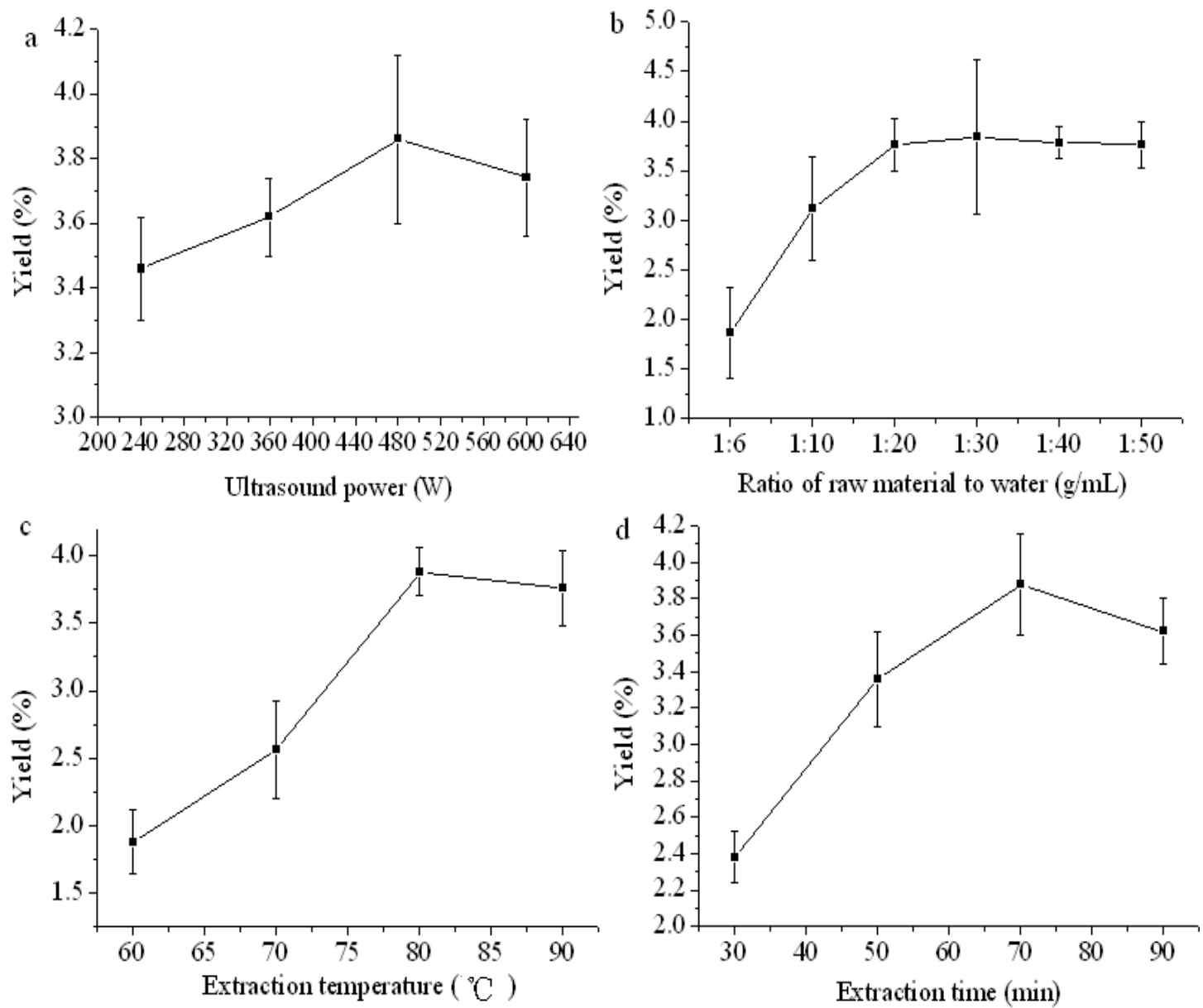

Figure 1: Effects of different factors on extraction yield of polysaccharide: ultrasound power (a), ratio of raw material to water (b), extraction temperature (c), and extraction time (d). All data were mean values of triplicate. The vertical error bars represented the standard deviation of each data point $(P<0.05)$ 
Table 2: Results of orthogonal experiment

\begin{tabular}{|c|c|c|c|c|c|}
\hline No. & $\begin{array}{l}\text { A (Ultrasonic } \\
\text { power W) }\end{array}$ & $\begin{array}{l}B \text { (ratio of raw } \\
\text { material to water } \\
\mathrm{g} / \mathrm{mL} \text { ) }\end{array}$ & $\begin{array}{l}\mathrm{C} \text { (extraction } \\
\text { Temperature }{ }^{\circ} \mathrm{C} \text { ) }\end{array}$ & $\begin{array}{l}\text { D (extraction } \\
\text { time min) }\end{array}$ & $\begin{array}{c}\text { Yield (\%, } n= \\
\text { 3) }\end{array}$ \\
\hline 1 & 1 & 1 & 1 & 1 & 3.84 \\
\hline 2 & 1 & 2 & 2 & 2 & 4.37 \\
\hline 3 & 1 & 3 & 3 & 3 & 3.73 \\
\hline 4 & 2 & 1 & 2 & 3 & 3.88 \\
\hline 5 & 2 & 2 & 3 & 1 & 3.67 \\
\hline 6 & 2 & 3 & 1 & 2 & 3.95 \\
\hline 7 & 3 & 1 & 3 & 2 & 3.08 \\
\hline 8 & 3 & 2 & 1 & 3 & 3.34 \\
\hline 9 & 3 & 3 & 2 & 1 & 4.01 \\
\hline $\mathrm{k} 1$ & 3.980 & 3.600 & 3.710 & 3.840 & \\
\hline $\mathrm{k} 2$ & 3.831 & 3.792 & 4.087 & 3.798 & \\
\hline k3 & 3.479 & 3.898 & 3.493 & 3.652 & \\
\hline $\mathrm{R}$ & 0.501 & 0.298 & 0.594 & 0.188 & \\
\hline
\end{tabular}

Table 3: ANOVA data of the orthogonal experiment

\begin{tabular}{llllll}
\hline Factor & SS & Df & MS & F-value & $P$-value \\
\hline A (ultrasonic power) & 1.192 & 2 & 0.596 & 7.584 & 0.004 \\
B (ratio of raw material to water) & 0.410 & 2 & 0.205 & 2.610 & 0.101 \\
C (extraction temperature) & 1.623 & 2 & 0.811 & 10.323 & 0.001 \\
D (extraction time) & 0.175 & 2 & 0.087 & 1.111 & 0.351 \\
Error (\%) & 1.415 & 18 & 0.079 & &
\end{tabular}

Note: $S S=$ sum of squares; $D F=$ degree of freedom; $M S=$ mean square
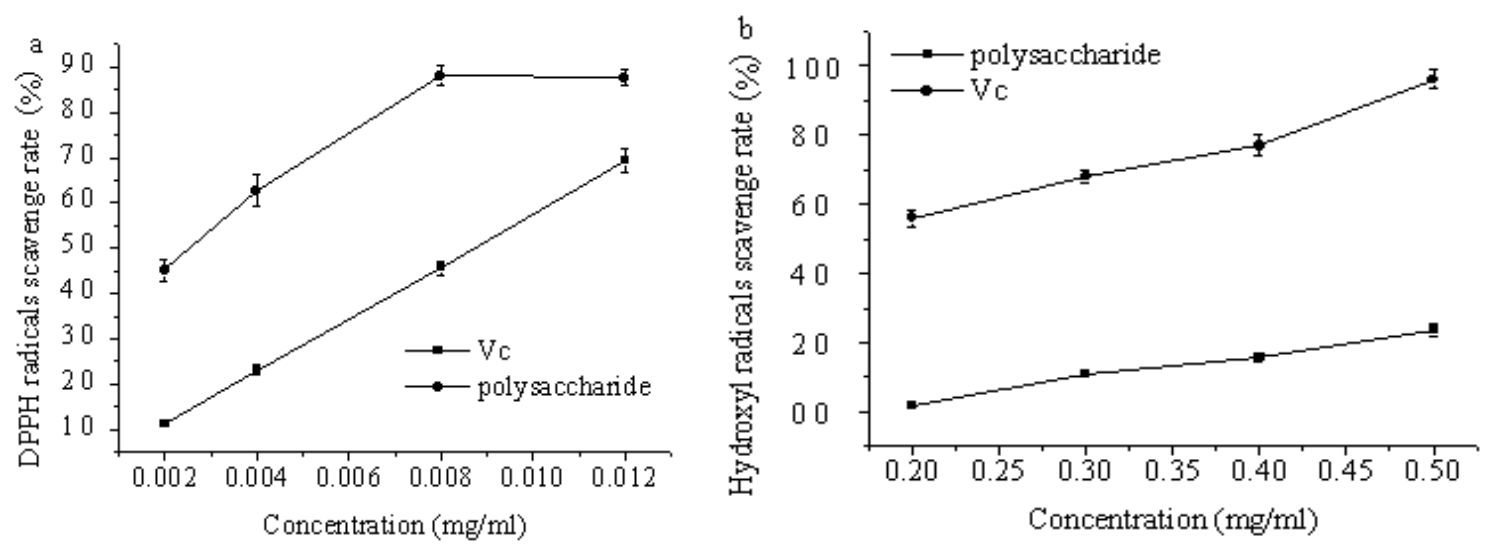

Figure 2: Antioxidant activities of polysaccharide from C. songaricum. (a) Scavenging activity of DPPH radical. (b) Scavenging ability of hydroxyl radicals. Data were shown as mean value of three parallel tests. The vertical bars represented the standard deviation of each data point $(p<0.05)$

The results indicated that factor $C$ was the most significant factor contributing to the extraction efficiency of polysaccharides, followed by factor $A$, factor $B$, and factor $D$. The optimum condition was obtained by orthogonal design, and was recommended as follows: ultrasonic power 420 $W$, ratio of raw material to water $1: 30 \mathrm{~g} / \mathrm{ml}$, extraction temperature $80^{\circ} \mathrm{C}$, and extraction time $70 \mathrm{~min}$. To test the reliability of the commended method, The polysaccharides was extracted for five times under above conditions, and results showed that experimental value $4.51 \%(n=5$,
RSD $=1.98 \%$ ) was consistent with the predictive values.

\section{Radicals scavenging activity}

\section{Scavenging activity of DPPH radicals}

The scavenging ability on DPPH radicals for polysaccharide extracted from $C$. songaricum and ascorbic acid were measured respectively, the results were shown in Figure $2 a$. With the concentration of polysaccharide increasing from $0.002 \mathrm{mg} / \mathrm{mL}$ to $0.012 \mathrm{mg} / \mathrm{mL}$, the $\mathrm{DPPH}$ radical 
scavenging activity increased all the time until reached to $64.82 \%$, and the maximum scavenging rate of ascorbic acid could reach $88.61 \%$ at $0.008 \mathrm{mg} / \mathrm{mL}$. This manifested that the polysaccharide from $C$. songaricum had a strong scavenging ability on DPPH radicals.

\section{Scavenging activity of hydroxyl radicals}

The result of hydroxyl radical scavenging activities of the polysaccharide was given in Figure 2b, which showed the difference of scavenging activity between the polysaccharide and ascorbic acid. Ascorbic acid was used as positive control. The scavenging activity increased significantly in a concentrationdependent way with polysaccharide concentration range of $0.2-0.5 \mathrm{mg} / \mathrm{mL}$, and achieved maximum value of $18.36 \%$ at 0.5 $\mathrm{mg} / \mathrm{mL}$, however the maximum scavenging activity of ascorbic acid was $91.71 \%$ at 0.5 $\mathrm{mg} / \mathrm{mL}$, which indicated that hydroxyl radicals scavenging activities of polysaccharide were not obvious compared with the ascorbic acid.

\section{DISCUSSION}

Instead of conventional extraction methods including fluid extraction, Soxhlet extraction, supercritical or subcritical extraction and pressurized liquid extraction, polysaccharides were extracted from $C$. songaricum Rupr using ultrasonic-assisted extraction in this study. Because ultrasonic extraction could obtain higher efficiency of extraction and more healthy extractive by reducing the handling time and use of solvent; meanwhile, its low operated temperatures can reduce the heat loss caused by high temperatures; in addition, it also prevents the vaporization of solvent during boiling and preserves bioactive substance. It is very useful for the extraction of thermolabile compounds $[18,19]$. In the present study, the best extraction technological parameters for polysaccharides from $C$. songaricum using ultrasonic-assisted extraction procedure is being reported for the first time. The ultrasound-assisted extraction parameters were optimized (ultrasonic power, extraction temperature, extraction time, and ratio of raw material to water) for increase extraction efficiency of the polysaccharides from $C$. songaricum by orthogonal experimental design. We found that the ultrasonic power and extraction temperature were significant for the polysaccharide extraction from $C$. songaricum at the $99 \%$ confidence level. While Ajaz Ahmad [19] found that the extraction temperature was an important factor for extraction efficiency of the polysaccharide at the $95 \%$ confidence level in optimal conditions of ultrasonic-assisted extraction of polysaccharides from Paeonia emodi. The $p$-value was used as evaluation index to check the significance of each coefficient and the interaction strength between variables [20].

Polysaccharides have been studied profoundly as additives in food and pharmaceutical applications due to their unique bioactivity $[21,22]$. We just determined the scavenging ablity on hydroxyl and DPPH radicals in vitro. Several studies have also reported that polysaccharides obtained by ultrasound treatment have different antioxidant activities depending on the extraction conditions (e.g., ultrasound power, extraction time, and extraction temperature) [23]. Some reports indicated that polysaccharide extracted by ultrasonic-assisted extraction had higher antioxidant activities than those polysaccharide extracted by enzyme-assisted extraction [24]. But the extraction technology of polysaccharides from $C$. songaricum and its bioactivities need to be further studied.

\section{CONCLUSION}

The four parameters (ultrasonic power, ratio of raw material to water, extraction temperature, and extraction time) tested in UAE were optimized by orthogonal design. The yield of polysaccharides was as high as $4.51 \%$ under the optimized extraction conditions as follows: $1: 30$ as ratio of raw material to water, extraction for $70 \mathrm{~min}$ at $80{ }^{\circ} \mathrm{C}$ with ultrasonic power being $420 \mathrm{~W}$. The polysaccharides extracted from $C$. songaricum showed significant antioxidant activity.

\section{ACKNOWLEDGEMENT}

This research was supported by Agricultural Scientific Research Projects: Forage Feed Resources Development and Utilization of Technology Research and Demonstration, China (no. 201203042), Chinese National Natural Science Foundation (31460032) and Natural Science Foundation of Gansu Province, China (nos. 1212RJYA008 and 1308RJZA287).

\section{REFERENCES}

1. Chu $Q$, Tian $X$, Lin M, Ye J. Electromigration profiles of Cynomorium songaricum based on capillary electrophoresis with amperometric detection. J Agric Food Chem 2006; 54: 7979-7983. 
2. Jiang Z. H., Tanaka T, Sakamoto M, Jiang T, Kouno I. Studies on a medicinal parasitic plant: Lignans from the stems of Cynomorium songaricum. Chem Pharm Bull 2001; 49: 1036-1038.

3. Qi Y, Su G.E. Progress in the research of Cynomorium (Cynomorium songaricum). Zhongcaoyao 2000; 31: 146-148.

4. Lu Y, Wang QG, Melzig MF, Jenett SK. Extracts of Cynomorium songaricum Protect SK-N-SH Human Neuroblastoma Cells against Staurosporine-induced Apoptosis Potentially through their Radical Scavenging Activity. Phytother. Res.2009; 23: 257261

5. Chen XP, Wang WX, Li SB, Xue JL, Fan LJ, Sheng ZJ, Chen YG. Optimization of ultrasound-assisted extraction of Lingzhi polysaccharides using response surface methodology and its inhibitory effect on cervical cells. Carbohyd Polym 2010; 80: 944-948.

6. Zhu ZY, Liu RQ, Si CL, Zhou F, Wang YX, Ding LN, Jing $C$, Liu AJ, Zhang YM. Structural analysis and antitumor activity comparison of polysaccharides from Astragalus. Carbohyd Polym 2011; 85: 895-902.

7. Shi YL, Yang $L H$, Cai $D H$. The effect of pleurotus eryngii polysaccharide on exhausted mice's resistance to oxidation and injury. J Phys Educ 2005; 12: 56-58. (in Chinese)

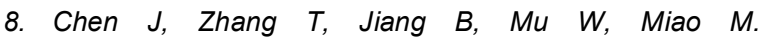
Characterization and antioxidant activity of Ginkgo biloba exocarp polysaccharides. Carbohyd Polym 2012; 87: 40-45.

9. Chen W, Wang WP, Zhang HS, Huang Q. Optimization of ultrasonic-assisted extraction of water-soluble polysaccharides from Boletus edulis mycelia using response surface methodology. Carbohyd Polym 2012; 87: 614-619.

10. Yi Y, Zhang MW, Liao ST, Zhang RF, Deng YY, Wei ZC, Tang $X J$, Zhang $Y$. Structural features and immunomodulatory activities of polysaccharides of longan pulp. Carbohydrate Polymers 2012; 87: 636643.

11. Wang $L C$, Zhang $K$, Di $L Q$, Liu R, Wu H. Isolation and structural elucidation of novel homogenous polysaccharide from Mactra veneriformis. Carbohyd Polym 2011; 86(2): 982-987.

12. Yi Y, Zhang MW, Liao ST, Tang XJ, Zhang RF, Wei ZC. Optimization of ultrasonic-enzyme-assisted extraction technology of polysaccharides from Longan pulp. $T$ Chinese Soc Agr Mach 2010; 41: 131-136.

13. Hromadkova Z, Ebringerova A. Ultrasonic extraction of plant materials investigation of hemicellulose release from buck wheat hulls. Ultrason Sonochem 2003; 10:127-133.
14. Xie JH, Shen MY, Xie MY, Nie SP, Chen Y, Li C. Ultrasonic-assisted extraction, antimicrobial and antioxidant activities of Cyclocarya paliurus (Batal.) Iljinskaja polysaccharides. Carbohyd Polym2012; 89: 177-184.

15. Zhang Q, Zhang TM. Determination of polysaccharide content by phenol-sulfuric acid method. Shandong Food Sci Technol 2004; 13: 17-18. (in Chinese)

16. Jin M, Cai $Y X, L i J R$, Zhao H. 1, 10-Phenanthroline$\mathrm{Fe} 2+$ oxidative assay of hydroxyl radical produced by H2O2/Fe2+. Prog. Biochem. Biophys 1996; 23: 553555.

17. Shimada K, Fujikawa K, Yahara K, Nakamura $T$. Antioxidative properties of xanthan on the autoxidation of soybean oil in cyclodextrin emulsion, $J$ Agric Food Chem 1992; 40: 945-948.

18. Wen $H$, An X, Hai $N$, Zhen J, Jiawen W. Optimised ultrasonic-assisted extraction of flavonoids from Folium eucommiae and evaluation of antioxidant activity in multi-test systems in vitro. Food Chem 2009; 114: 1147-1154.

19. Ahmad A, Alkharfy K M, Wani T A, Mohammad R. Application of Box-Behnken design for ultrasonicassisted extraction of polysaccharides from Paeonia emodi. Int J Biol Macromol 2015; 72: 990-997.

20. Karacabey E, Mazz G. Optimisation of antioxidant activity of grape cane extracts using response surface methodology. Food Chem 2010; 119: 343-348.

21. Bendjeddou $D$, Lalaoui $K$, Satta $D$. Immunostimulating activity of the hot water-soluble polysaccharide extracts of Anacyclus pyrethrum, Alpinia galanga andCitrullus colocynthis. J Ethnopharmacol 2003; 88: 155-160.

22. Tian Z, Yong C. S, Ming Q. F, Ren X. T. Cloning, expression and biochemical characterization of UDPglucose 6-dehydrogenase, a key enzyme in the biosynthesis of an anti-tumor polysaccharide from the marine fungus Phoma herbarum YS4108. Process Biochem 2011; 46: 2263-2268.

23. Bao Y, Mouming Z, John SH, Ning Y, Yueming J. Effect of ultrasonic treatment on the recovery and $D P P H$ radical scavenging activity of polysaccharides from longan fruit pericarp. Food Chem 2008; 106: 685690.

24. Ningbo $L$, Jianjun $Z$, Xingqian $Y$, Shan $L$, Wenjun $W$, Ronghua $\mathrm{ZH}$, Jian $X$, Shiguo $\mathrm{CH}$, Donghong $\mathrm{L}$. Ultrasonic-assisted enzymatic extraction of polysaccharide from Corbicula fluminea: Characterization and antioxidant activity. LWT-Food Sci Tech 2015; 60: 1113-1121. 